\title{
Identifying House Price Booms, Bubbles and Busts: A Disequilibrium Analysis from Chaos Theory
}

\author{
Gerald A. Hanweck \\ School of Business, George Mason University, Fairfax, VA, USA \\ Email: ghanweck@gmu.edu
}

How to cite this paper: Hanweck, G.A. (2020) Identifying House Price Booms, Bubbles and Busts: A Disequilibrium Analysis from Chaos Theory. Journal of Mathematical Finance, 10, 448-463.

https://doi.org/10.4236/jmf.2020.103027

Received: April 5, 2020

Accepted: August 25, 2020

Published: August 28, 2020

Copyright $\odot 2020$ by author(s) and Scientific Research Publishing Inc. This work is licensed under the Creative Commons Attribution International License (CC BY 4.0).

http://creativecommons.org/licenses/by/4.0/ (c) (i) Open Access

\begin{abstract}
This research was motivated by the excesses of public policy since 2008 in an attempt to re-inflate the housing markets. Is it even possible or desirable to utilize such a vast amount of public resources to inflate a single sector such as housing that suffered from such a spectacular bubble and collapse? The consequences suggest that, as a way to bolster real household incomes and aggregate output, these policies have disappointed. In contrast, there is a fear that the monetary stimuli will lead to unsustainable housing price inflation, if not a bubble. I address these questions in the analysis from the standpoint of determining the stable equilibrium and sustainable house price appreciation rates consistent with the growth of median household income. The problem of identifying stable house price appreciation is to first identify the major proximate determinants of household demand for housing. A second is to show empirically the movement, deviation, and variation of these factors over time compared to housing prices. I use median household income as the major demand factor for houses and median single family house prices as an indicator of the price. A third is determining the stable equilibrium of the growth of these factors and the appreciation of housing prices consistent with them. And a fourth is the adjustment process when there are small deviations from steady-state equilibrium compared to when deviations are large. It is this last distinction where the chaos theory of self-organizing systems and irreversibility of the housing market system enters to explain how the adjustment process is chaotic in this case. I conclude that, as of the beginning of June 2016, the evidence is overwhelming that housing price appreciation is in a bubble that will likely lead to significant declines in house price appreciation if not in house prices. An important policy recommendation to mitigate these declines and hasten a house price recovery follows. The continuation of expansionary monetary policies will only delay house price adjustments and
\end{abstract}


lead to more severe price declines.

\section{Keywords}

Housing Prices, Chaos Theory, House Price Booms, House Price Busts, Housing Price Steady-State Equilibria, House Price Instability

\section{Introduction}

This research was motivated by the excesses of public policy attempting to re-inflate the housing market after the disastrous collapse of house prices from mid-2006 to the approximate beginning of a turnaround in March 2012 (Figure 1). The public policy includes the various mortgage restructuring policies of the Federal Government, such as HAMP and HARP, and the massive purchases by the Federal Reserve in its various Quantitative Easing Policies, QEs, starting in 2010 by buying nearly all the newly minted mortgage backed securities from Freddie Mac and Fannie Mae, the two GSEs placed in conservatorship in the Fall of 2008, and various longer term maturities of U.S. Treasury securities. Although, house prices have been increasing since 2012, as of February 2016 they remained below the peaks that were set in mid-2006 and only regained these highs in November 2016, over 10 years in the making (Figure 1).

Why have these unprecedented policies been so ineffective in inflating house prices until 2012 and will they end in an unsustainable housing price boom if they persist for much longer? The Fed has added over $\$ 4.5$ trillion to its balance sheet by the massive QEs and announced the end of these policies in October 2014, but retained reinvestment of principal payments in RMBS. Considering the magnitude of the Federal Reserve actions, the value of residential properties should have risen by much more than they did. According to the Flow of Funds accounts, the total rise in residential property values from the low point in 2011 Q2 of \$16.2 trillion to 2016 Q4 was \$6.9 trillion and was only \$1.6 trillion or 2.7 percent above the peak value set in 2006 Q4 of $\$ 22.5$ trillion. ${ }^{1}$ [1] These lackluster results are confirmed by other data such as median existing house prices that peaked to over $\$ 245,400$ in 2006 and recovered to that level in 2012, 6 years into recovery (Figure 2). ${ }^{2}$ [2] However, by 2016 median house prices had risen by 27 percent to $\$ 318,600$. Perhaps even more profound is that real median household income in the U.S. fell by -1.3 percent from 2007, the start of the Great Recession, to 2016 (the latest data available) to levels equivalent to those in 1998 and recovery has been slow since its start (Figure 3 and Figure 4). Is it even possible ${ }^{1}[1]$ Board of Governors of the Federal Reserve System, Flow of Funds Accounts, Table B.101 for various years.

${ }^{2}$ The source of data for median house prices is [2] National Association of Realtors, Median Sales Price of Existing Homes, various dates. However, by December 2015 median house prices had reached $\$ 308,100$ ([3] U.S. Census, May 26, 2016) and new median house prices at about the same (Figure 2). 
or desirable to successfully utilize such a vast amount of public resources to inflate a single sector such as housing that suffered from such a spectacular bubble and collapse? The consequences appear to suggest that as a way to bolster real household incomes and real output, these policies have been a disappointment. In contrast, is there a fear that the monetary stimulus will lead only to serious and unsustainable house price inflation, if not a bubble? I will address these questions in the remainder of the analysis from the standpoint of the determination of what are possible stable steady-state equilibria and sustainable house price appreciation rate consistent with the growth of nominal median household income. (George Mason University, School of Business)

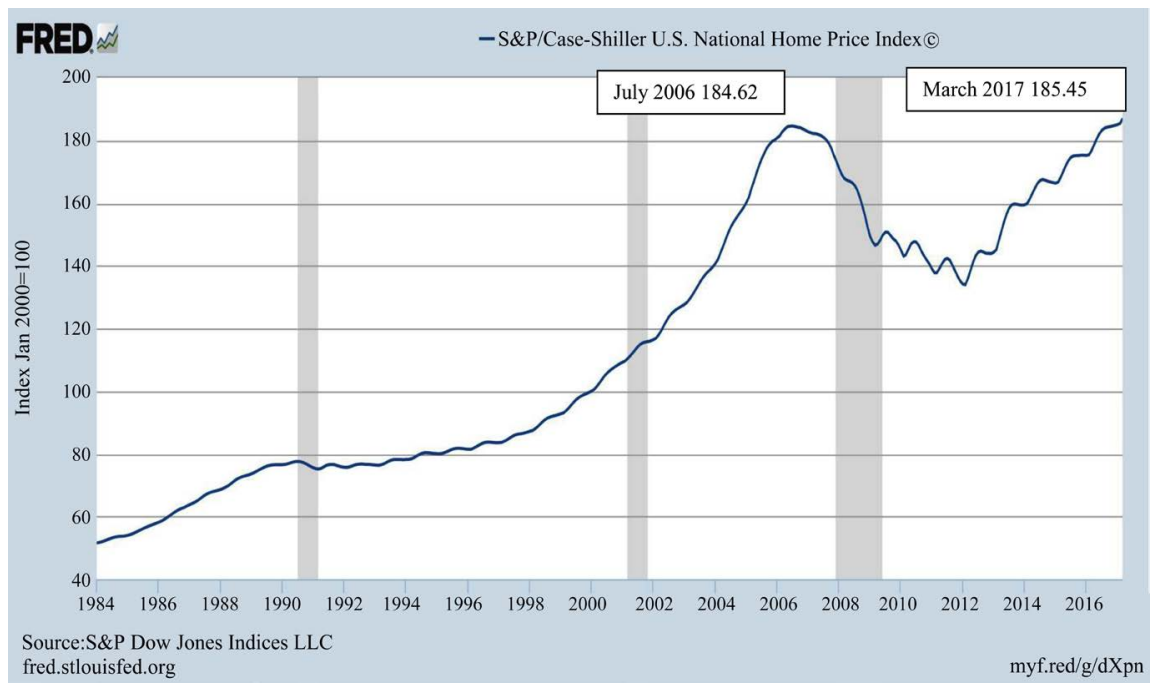

Figure 1. Case-Shiller U.S. national home price index (monthly, 011984 to 03 2017). Source: FRED Economic Data, Federal Reserve Bank of St. Louis.

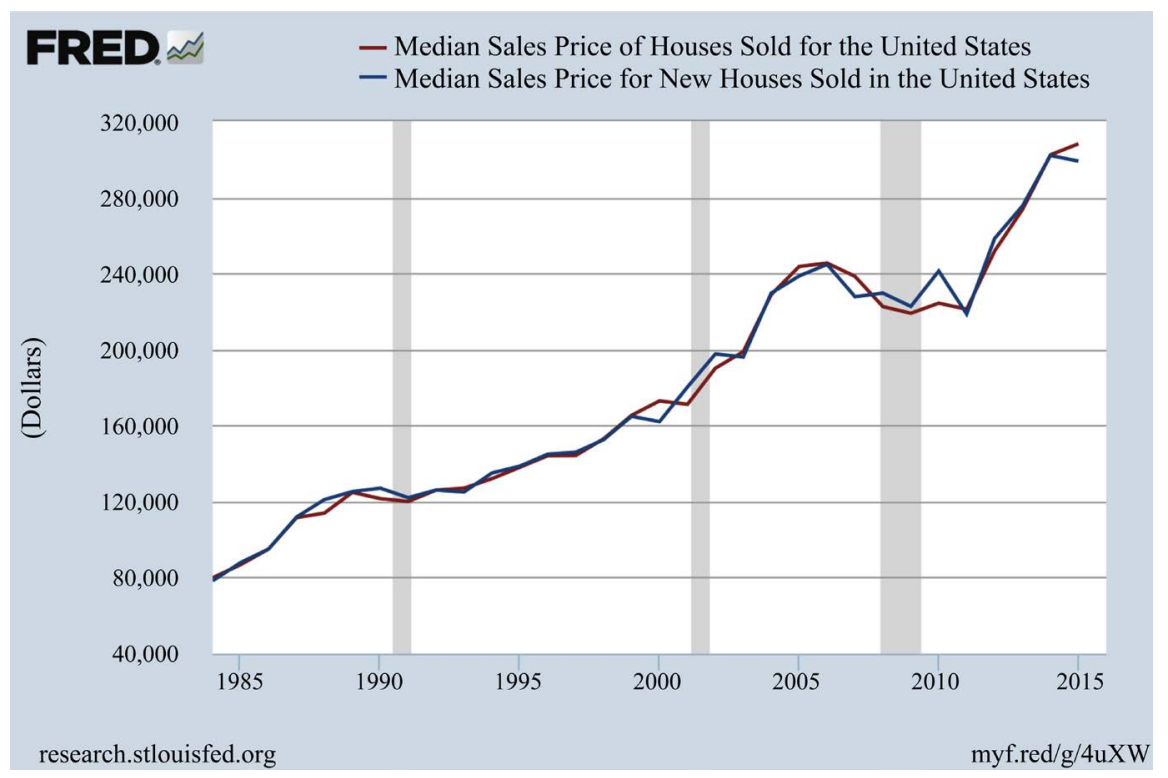

Figure 2. Median sales price of houses and new houses in U.S. (annually, 1984-2016). Source: Federal Reserve Bank of St. Louis, FRED database. 


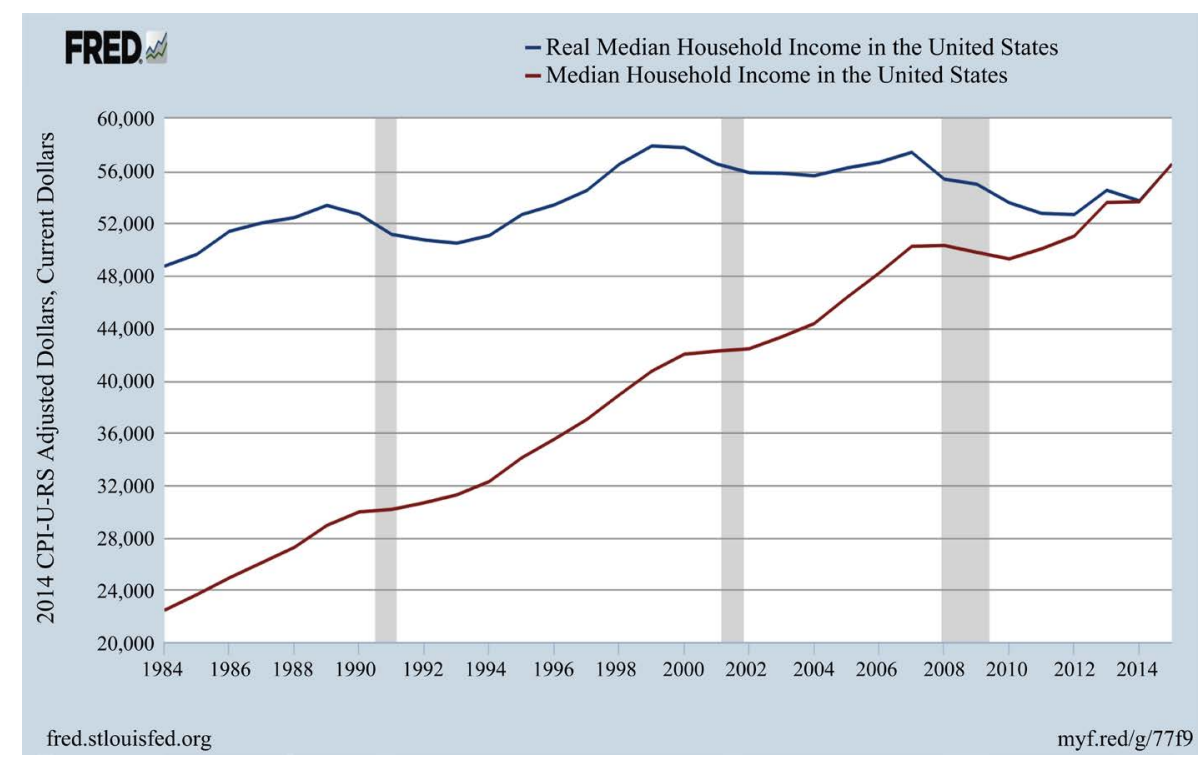

Figure 3. Nominal and real median household income (annually, 1984-2015). Source: Federal Reserve Bank of St. Louis, FRED database, May 2016.

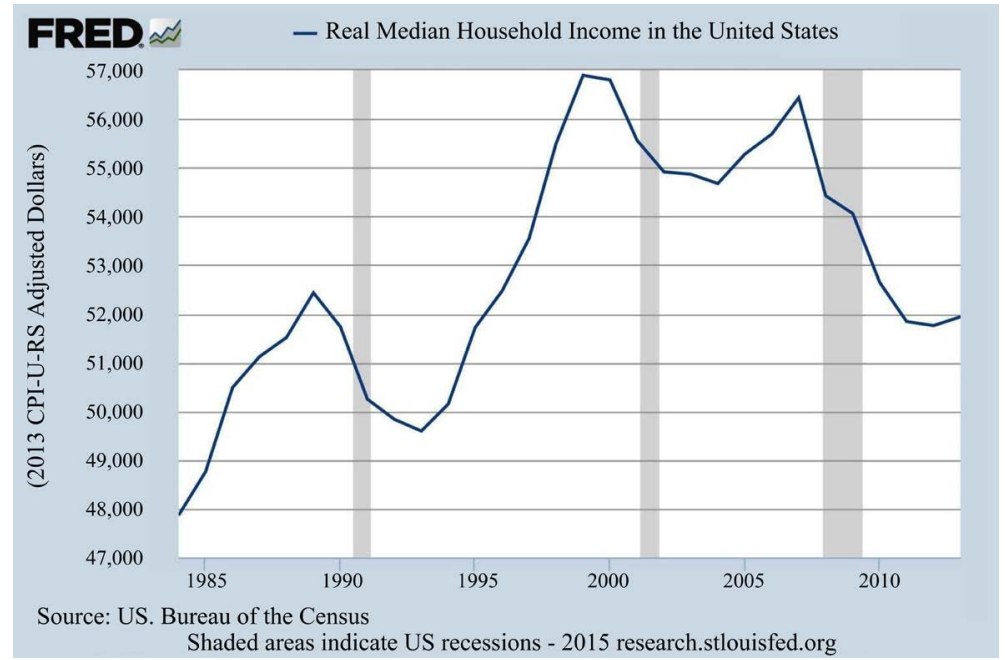

Figure 4. Real median household income (annually, 1984-2013). Source: Federal Reserve Bank of St. Louis, FRED database.

\section{Analysis of House Prices and Household Income during the Boom and Bust}

The problem of identifying stable house price appreciation is to first identify the major proximate determinants of household demand for housing. A second is to show empirically the movement, deviation, and variation of these factors over time compared to house prices. A third is determining the stable equilibrium of the growth of these factors and the appreciation of house prices consistent with them. And fourth, the adjustment process when there are small deviations from equilibrium compared to when deviations are large. It is this last distinction where the theory of self-organizing systems and irreversibility of the housing market system enters to explain how the adjustment process is chaotic when 
large deviations from equilibrium occur.

Realized and Expected Household Income: Major Determinants of the Demand for Housing

For most households, there is a threshold income that will determine their demand for the purchase of a house. Whether it is the necessary cash flow to meet the mortgage payments given all other debt service and living expenses or whether it is for a particular level of house price (a more expensive upper grade house in a particular neighborhood), households must feel comfortable within these constraints. Certainly the cost of mortgage service, interest, taxes, insurance premiums and principal payment, are all considered by households in determining whether to buy a house or upgrade or not. But these are only basic cash flow factors, choosing a house encompasses psychological and demographic needs in addition to simple cash flow needs. Households also consider their expected future incomes and the need for a particular location for schools, proximity to work or transportation. If households expect future incomes to rise and be stable at higher amounts, they may be more willing to take on the more expensive house that best fits their other needs and meet higher expenses in the future while scrimping now. This may be considered speculation, but they are not wagering that the value of the property will appreciate for them to receive value from the house. In a sense though, households are speculating that higher incomes will be realized and they will "grow" into their housing expenses. In such cases we should observe that the equilibrium ratio of median house prices to median household incomes rise over time the more optimistic households become. If households did not anticipate with some reasonable degree of certainty that their incomes would rise they would have either not bought or bought a less expensive property. In this case this ratio would remain constant or not rise appreciably.

In periods of euphoria when the widely held expectation that housing prices will continue to rise indefinitely, as in the housing price boom of the early to mid-2000's, the ratio of median housing prices to median household income should soar (2001 to 2006, Figure 5). In contrast, once euphoria turns to disappointment, realizations are less than expectations, housing prices slow down or begin to fall absolutely and the ratio of median house price to median household income declines (2006 to 2011, Figure 5).

The evidence follows this pattern. In 2001, just before the house price boom set in, the ratio of median house prices to median household income was 4.16 times (Figure 5). By the peak of the house price boom this ratio was 5.26 times in 2005. Once the price bust started, it fell until 2009 to 4.4 times and settled in 2011 at 4.42. It has since risen dramatically to 5.63 in 2016, by 27 percent and seems to have settled between 5.45 and 5.63. It is notable that as real median household income has not risen, house prices are rising at a more rapid rate than nominal household income. This ratio has now risen to levels exceeding that during the time of the greatest house price bubble of the late- $20^{\text {th }}$ and early- $21^{\text {st }}$ centuries. 


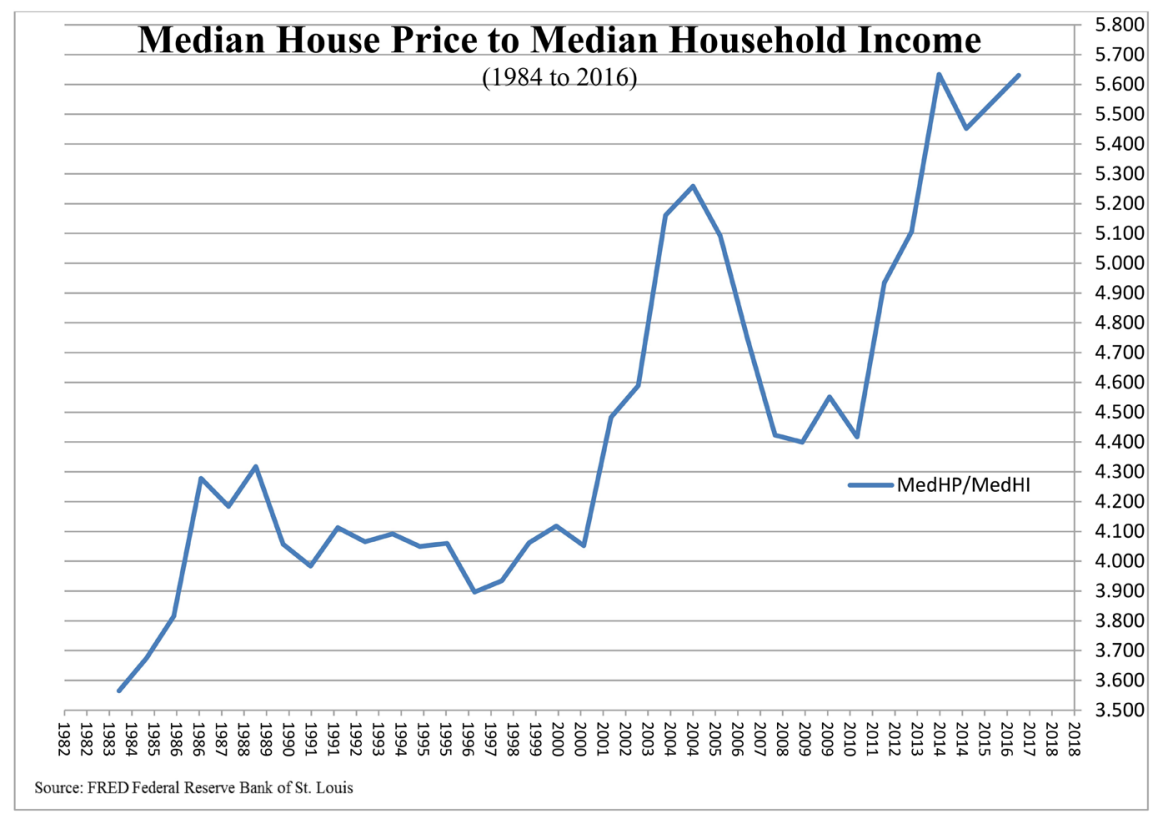

Figure 5. Median house price to median household income (annually, 1984 to 2016). Source: Data items from Federal Reserve Bank of St. Louis, FRED database and author's computation.

\section{When Is Housing Price Appreciation Stable?}

Housing prices have been through vast changes over the past 25 years, hitting peaks in 2006 and falling back to levels of early 2003 in late 2012 (Figure 1). What is abundantly clear is that house prices are highly volatile. There have been a number approaches suggested by economists to mitigate and hedge these large price variations such as futures markets in house prices (see [4] Bertus, Hollans and Swidler (2008), [5] Englund, Hwang and Quigley (2002), [6] Fan, Pu and Ong (2012), [7] Lee Stevenson and Lee (2014), [8] Shiller (1990), [9] Voicu and Siler (2013), [10] Wong, Yiu, Tse, and Chau (2006) and [11] Wong, Chau, and Yiu (2007) for example). But what is the level or rate of appreciation where house prices can be considered stable or their appreciation can be considered stable? In other words, is there an appreciation rate for house prices that can be unambiguously identified as not being a boom, bubble or bust, but stable? (see [12] Abreu, and Brunnermeier (2003), [13] Flood and Hodrick (1990), [14] Stiglitz (1990), and [15] Evans, George (1991))

The model, proposed here to address this question, is based on the assumption that the fundamental foundational factor influencing the growth in the demand for housing is the growth in nominal household income. In the aggregate, this factor is measured by the nominal median household income as published by the [3] Bureau of Census and is shown in Figure $3 .^{3}$ Barring periods of euphoric or depressing expectations or historically low interest rates, the growth of incomes of households is fundamental to a stable growing demand for housing ${ }^{3}$ Unfortunately, the frequency of these data are only available annually which limits cyclical and seasonal variation analysis. 
and pressure for housing prices to increase.

The implication suggested by this simple model is that the ratio of median house prices to median household income ought to approach a constant (or a long run trending value) as it adjusts from boom periods or bust periods. Using the ratio of the median house price to nominal median household income as a proxy in the aggregate, the movement of this ratio from 1984 to 2016 is shown in Figure 5. From these data a singular value is not immediately apparent except for the period 1984 to 2001. After 2001, an upward trend developed that has been motivated by the huge housing price boom and the aftermath of the bust. This has led to a moderate upward trend over time, but again there is little obvious from these data except that the boom time of the period from 2001 to 2006 and the current surge since 2012 are very evident. In addition there is no evidence that this ratio is settling down to levels that existed from 1984 to 2001, a period of 17 years, of highly volatile interest rates, the Thrift Crisis, 3 recessions, the Dot-Com boom and 2 wars. Our approach is to decompose the ratio of MHP to $\mathrm{MHI}$ in order to ascertain ranges of stability in the housing price ratio.

\section{A Disequilibrium Analysis from Chaos Theory Applied to Housing}

\subsection{A Deterministic, Non-Stochastic Approach}

Equilibrium of the median house price (MHP) to median household income (MHI) ratio ( $R$ ) - MHP/MHI - has two components: 1) the level of the ratio and 2) the steady state where the ratio does not change or approaches no change. A proportional change in the ratio can be decomposed into a positive change and a negative change assuming the ratio is not stochastic:

$$
\frac{\frac{\mathrm{d}(\mathrm{MHP} / \mathrm{MHI})}{\mathrm{d} t}}{\mathrm{MHP} / \mathrm{MHI}}=\frac{\frac{\mathrm{dMHP}}{\mathrm{d} t}}{\mathrm{MHP}}-\frac{\frac{\mathrm{dMHI}}{\mathrm{d} t}}{\mathrm{MHI}}=f_{+}-f_{-}
$$

The proportional change in the ratio $\mathrm{MHP} / \mathrm{MHI}$ is the difference of the proportional change in MHP and MHI $\left(f_{+}-f_{-}\right)$. The steady-state is where the proportional change in the ratio is zero and $f_{+}-f_{-}=0$.

However, this may or may not be a stable equilibrium depending on the stability conditions of the ratio and the momentum of either $f_{+}$or $f_{-}$succeeding or preceding a possible steady state value. A diagram from [16] Ilya Prigogine (p. 145), reproduced in Figure 6, illustrates this point. There are 4 possible steady state points shown in the diagram, but only one is a stable state with regard to positive and negative fluctuations in $X$ - SS is the point and discussed in the notes to Figure 6. At point SS, fluctuations that are to the left of the point will be pushed back toward increasing $X$ since positive changes are greater than negative changes and deviations to the right of SS will reduce $X$ since the negative fluctuations exceed the positive. For the MHI/MHP ratio there may be numerous values where the steady state is reached and a stable equilibrium is attained 
and many where it is not. In fact, the ratio could cycle around the stable equilibrium as suggested in Figure 6 of Prigogine [16] as deviations from equilibrium take place $-X$ will decrease then increase perhaps past the equilibrium value and then turn back as negative rates of change factors are greater than positive factors (such as for point SS in Figure 6).

The data for the MPH/MPI ratio also reflect what [17] Sugihara, et al. (2012, p. 496) refer to in dynamic systems as "weak to moderate coupling." During the pre-2002 period the proportional changes in MHP and MHI had a statistically significant positive correlation of 0.60 (see Table 1 and Figure 7). However in the period from 2002 to 2016 the correlation was positive, but dropped to 0.07 and is not statistically significant (Table 1). This strongly suggests, following Sugihara, et al., that any relationship from MHI to MHP disappeared after 2001, the two components, $f_{+}$and $f_{-}$, had decoupled, and that the relationship of these factors to the MHP/MHI ratio had virtually uncoupled, compared to the prior years.

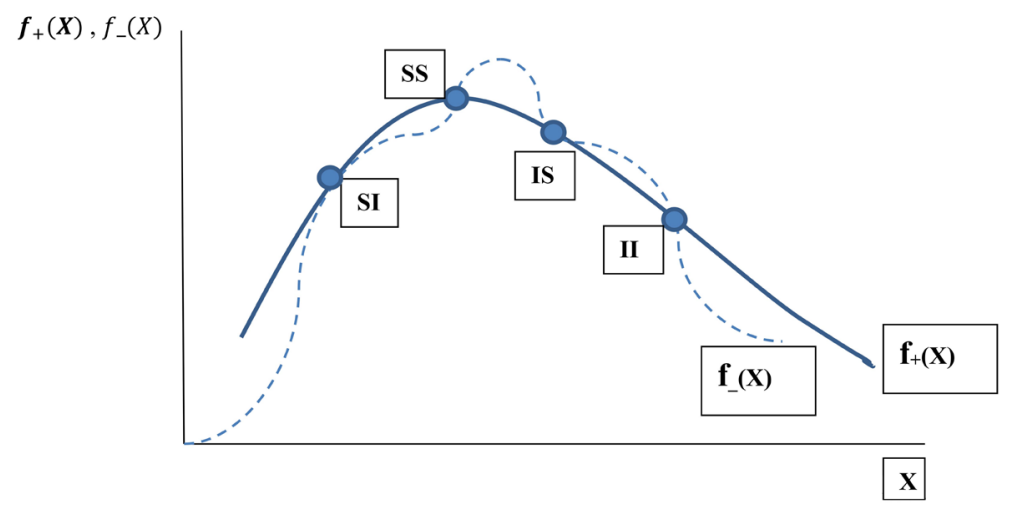

Figure 6. Catalytic loops and stable equilibria. "Catalytic loops correspond to nonlinear terms. In the case of a one-independent-variable problem, this means the occurrence of at least one term where the independent variable appears with a power higher than 1; in this simple case, it is easy to see the relation between such nonlinear terms and the potential instability of stationary states." "Let us take the independent variable $X$ the time evolution of $\mathrm{d} X / \mathrm{d} t=f(X)$. It is always possible to decompose $f(X)$ into (sic) two functions representing a gain and a loss $f_{+}(X)$ and $f_{-}(X)$, each of which is positive or 0 , such that $f(X)=f_{+}(X)-f_{-}(X)$. In this way, stationary states $(\mathrm{d} X / \mathrm{d} t=0)$ correspond to values where $f_{+}(X)=f_{-}(X)$." "Those states are graphically given by intersections of the two graphs plotting $f_{+}(X)$ and $f_{-}(X)$. If $f_{+}(X)$ and $f_{-}(X)$ are linear, there can be only one intersection. In other cases, the type of intersection permits us to infer the stability of the stationary state." "Four cases are possible:" "SI: stable with respect to negative fluctuations, unstable with respect to positive ones: If the system deviates slightly to the left of SI, the positive difference between $f_{+}(X)$ and $f_{-}(X)$ will reduce this deviation back to SI; deviations to the right will be amplified." "SS: stable with respect to positive and negative fluctuations." "IS: stable only with respect to positive fluctuations." "II: unstable with respect to positive and negative fluctuations." Source: Prigogine, Figure 4, p. 145. 


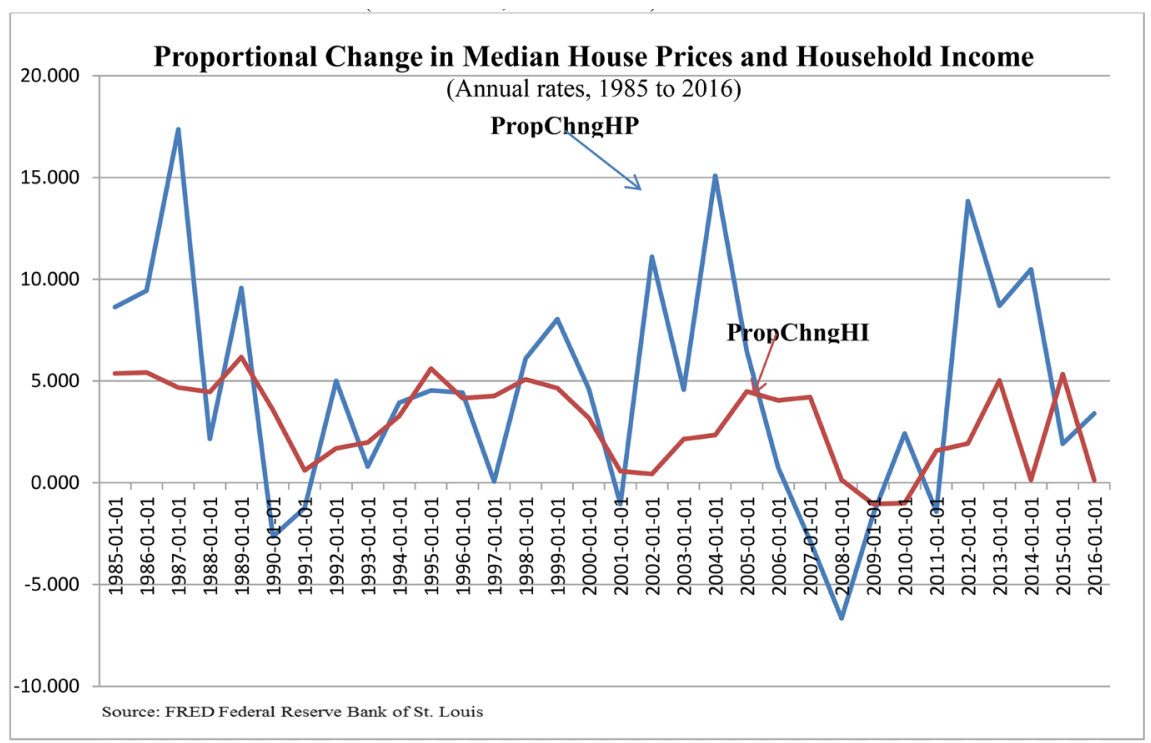

Figure 7. Proportional change in median house prices and median household income. (Annual rates, 1985 to 2016). Source: Data items from Federal Reserve Bank of St. Louis, FRED database and author computation.

Table 1. Parameters used in Monte Carlo simulations investigating alternative Steady-States.

\begin{tabular}{ccc}
\hline Parameter & $1985-2001$ & $2002-2016$ \\
\hline Mean $R$ & 4.18 & 4.87 \\
$\frac{\mathrm{d} R}{R}$ & 0.0075 & 0.0219 \\
Mean $f_{+}$ & 0.0469 & 0.0442 \\
Mean $f_{-}$ & 0.0381 & 0.0199 \\
$\sigma_{f_{+}}$ & 0.0501 & 0.0642 \\
$\sigma_{f_{-}}$ & 0.0171 & 0.0219 \\
$\rho_{f_{+}}$ & $0.6040^{* * *}$ & 0.1101 \\
\hline
\end{tabular}

*** Significantly different from zero at the 0.00001 level, except $\mathrm{d} R / R$ for 1985-2001 and the correlation for 2002-2016.

Is there any evidence of recoupling after the end of the Great Recession in 2009? The correlation between $f_{+}$and $f_{-}$over the 2009 to 2016 period was a larger 0.226 , but remained highly insignificant. Thus there may be some evidence of recoupling, but it remains weak and certainly well below the degree to which it was in the 1985 to 2001 period.

\subsection{A Stochastic, Dynamic Approach to a Steady State Analysis of the MHP/MHI Ratio}

In order to further consider the factors affecting the temporal dynamics of $f_{+}$and $f_{-}$, the proportional changes in MHP and MHI, one assumption might be that each follows an Ito process like that of Brownian motion. This process can be 
stated for each as:

$$
\begin{aligned}
& \mathrm{d} f_{+}=\mu_{f_{+}} \mathrm{d} t+\sigma_{f_{+}} \mathrm{d} \omega_{f_{+}}(t) \\
& \mathrm{d} f_{-}=\mu_{f_{-}} \mathrm{d} t+\sigma_{f_{-}} \mathrm{d} \omega_{f_{-}}(t)
\end{aligned}
$$

where MHP and MHI each are assumed to follow a separate lognormal distribution with different means and standard deviations respectively, $\mu_{f_{+}} \mathrm{d} t$ and $\mu_{f_{-}} \mathrm{d} t$ are drift terms, and $\mathrm{d} \omega_{f}(t)$ for each $f$ are Weiner processes (Normal distribution, with mean 0 and standard deviation 1 ).

However, this approach ignores any statistical relationship between $f_{+}$and $f_{-}$. To account for this we consider the stochastic process of the ratio of MHP to MHI, $R$. This can be written as:

$$
\frac{\mathrm{d} R}{R}=\mu_{R} \mathrm{~d} t+\sigma_{R} \mathrm{~d} \omega_{R}(t)
$$

where

$$
\begin{gathered}
\mu_{R} \mathrm{~d} t=\mu_{f_{+}} \mathrm{d} t-\mu_{f_{-}} \mathrm{d} t \\
\sigma_{R}=\left(\sigma_{f_{+}}^{2}+\sigma_{f_{-}}^{2}-2 \operatorname{Cov}\left(f_{+}, f_{-}\right)\right)^{1 / 2}
\end{gathered}
$$

In terms of the correlation between $f_{+}$and $f_{-}$Equation (7) can be restated as:

$$
\sigma_{R}=\left(\sigma_{f_{+}}^{2}+\sigma_{f_{-}}^{2}-2 \sigma_{f_{+}} \sigma_{f_{-}} \rho_{f_{+} f_{-}}\right)^{1 / 2}
$$

where $\rho_{f_{+} f_{-}}$is the correlation coefficient between these two rates of change.

Using these assumptions and results, the proportional change in $R$ can be rewritten as:

$$
\frac{\mathrm{d} R}{R}=\mu_{f_{+}} \mathrm{d} t-\mu_{f_{-}} \mathrm{d} t+\left(\sigma_{f_{+}}^{2}+\sigma_{f_{-}}^{2}-2 \sigma_{f_{+}} \sigma_{f_{-}} \rho_{f_{+} f_{-}}\right)^{1 / 2}\left(\mathrm{~d} \omega_{f_{+}}(t)+\mathrm{d} \omega_{f_{-}}(t)\right)
$$

A steady-state is where $\frac{\mathrm{d} R}{R}=0$. This occurs when the two drift terms offset each other and the volatility term is zero, or the difference in the drift terms are offset by the volatility term. Of course there is random movement due to the Weiner processes, but these are transitory random effects. If variances of the $f$ s are not stable or experience jumps that do not immediately dissipate, the steady-state could be sufficiently perturbed to move to a new level or wander about until there is a return to the initial or other steady state that may or may not be stable. To consider alternative steady-states' stability we will simulate alternatives using parameters of equation 8 for two periods of our data: 1985 to 2001 and 2002 to 2016, the pre-boom period and the boom and post-boom periods. Table 1 shows the value of the parameters that will be used in the simulations.

\subsection{Monte Carlo Simulations of $\frac{\mathrm{d} R}{R}$ Using Parameters for}

Periods 1985-2001 and 2002-2016

Analyzing the time series data for the two periods 1985-2001 and 2002-2016 
shows that the behavior of the parameter estimates and $\mathrm{d} R / R$ is distinctively different in the two periods (Table 1).

Viewing the data for the MHP/MHI ratio in the same way as Prigogine (Figure 6) does in Figure 8, with the ratio on the horizontal axis and the rates of change of $f_{+}$and $f_{-}$on the vertical axis, we find from this scatter plot that there appears to be a stable steady-state equilibrium between the values of the ratio at 3.6 to 4.1. There is a cycling (perhaps a limit cycle) about the MHP/MHI ratio of 4.065. This corresponds to the period between 1985 and 2001. After this there is some indication that a new sustainable equilibrium may arise in the neighborhood of 4.4 to 4.75 . However this deteriorated quickly over 3 years such that the ratio is now at the highest point it has ever been at 5.63, far from any of the possible sustainable steady-state equilibria. At this level of the MHP/MHI ratio, any natural forces that would push the ratio back near equilibrium are not present such that the "catalytic loop" providing the feedback from the ratio to future values is not present.

The natural adjustment process, the "catalytic loop", we are considering can take several forms. For example, if housing producers keep production at existing levels, the rise in housing prices will deter households from buying, increasing inventory of new and existing homes and lowering the appreciation in house prices or resulting in house price declines. The ratio would then adjust downward. Another equilibrating process is if housing producers expect rising prices, they may increase production and existing home owners will put their houses on the market increasing inventory and, given demand, lower house price appreciation or actual house prices. Taking these adjustment processes together, house prices will adjust to stable steady-state equilibrium. However, the farther the ratio gets from this equilibrium and the larger the difference between $f_{+}$and $f_{-}$, the greater the likelihood is that a return to equilibrium may require considerable declines in house price appreciation or house prices or unrealistically large increases in median family incomes.

The graph in Figure 9 shows the difference between $f_{+}$and $f_{-}$in a scatter diagram with the ratio of MHP/MHI. There is an apparent steady-state equilibrium at the ratio of MHP/MHI of 4.062 as the difference between $f_{+}$and $f_{-}$cycles around zero. As the ratio increases there is no other value with any cycling of $f_{+}$ - $f_{-}$or any movement toward zero except at the ratio of 4.552 . The ratio is moving away at a significant rate from these possible steady-state equilibria. These results are consistent with those of Figure 8.

We use Monte Carlo simulation to provide a degree of confirmation of these results. The simulations use Equation (9) above drawing 10,000 random samples for each Weiner process and using the parameters of each of the subperiods to do two simulations. The results are shown in Figure 10 for the 1985 to 2001 and 2002 to 2016 periods. The results indicate that the first period has a steady state at a ratio of 3.6 times and 4.6 times for the second period. A T-test of these differences shows that they are statistically significantly different at the 1 percent 
level with a t-statistic of 2.1. These results confirm that there is a different steady state at the pre-2002 period than for the post-2001 period and that the current value of the ratio of MHP/MHI at 5.63 is far from a potential steady state even for the post-2001 period and certainly for the pre-2002 period.

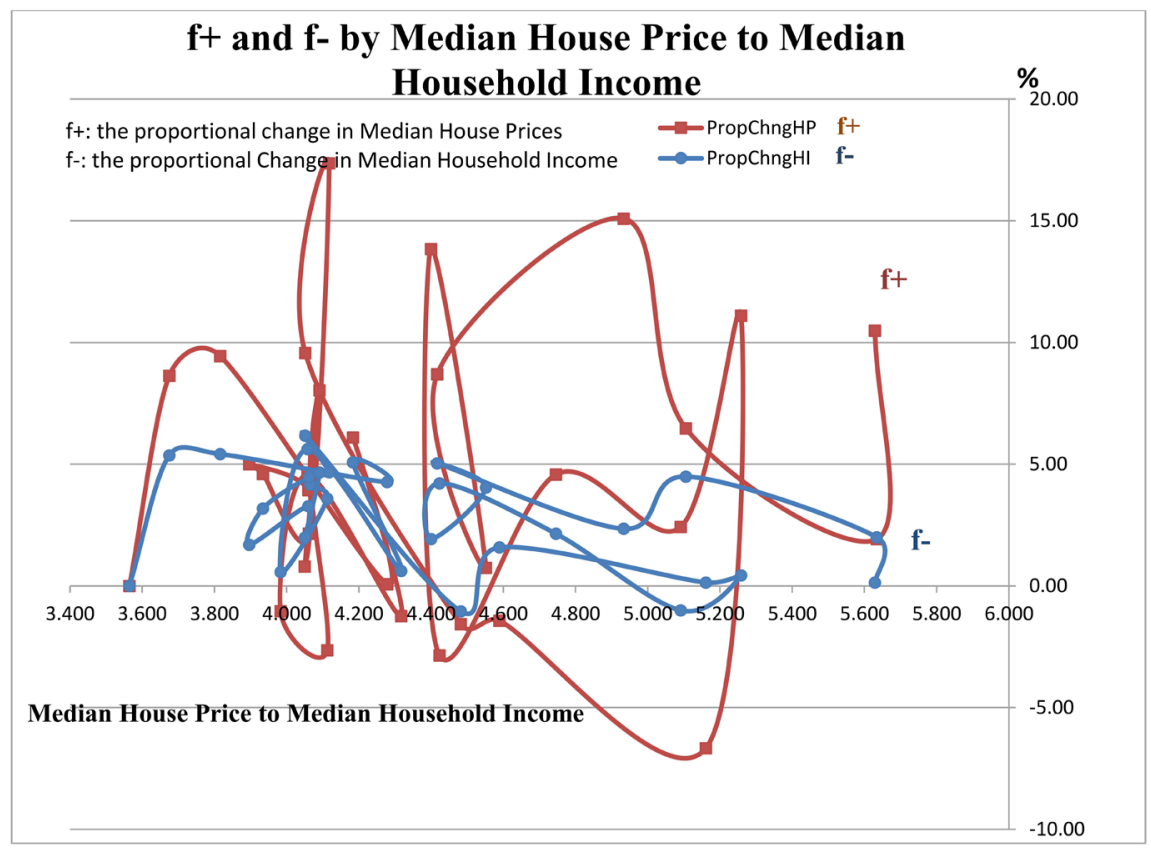

Figure 8. Comparison of rates of change of median house prices and median household income. Source: Data items from Federal Reserve Bank of St. Louis, FRED database and author computation.

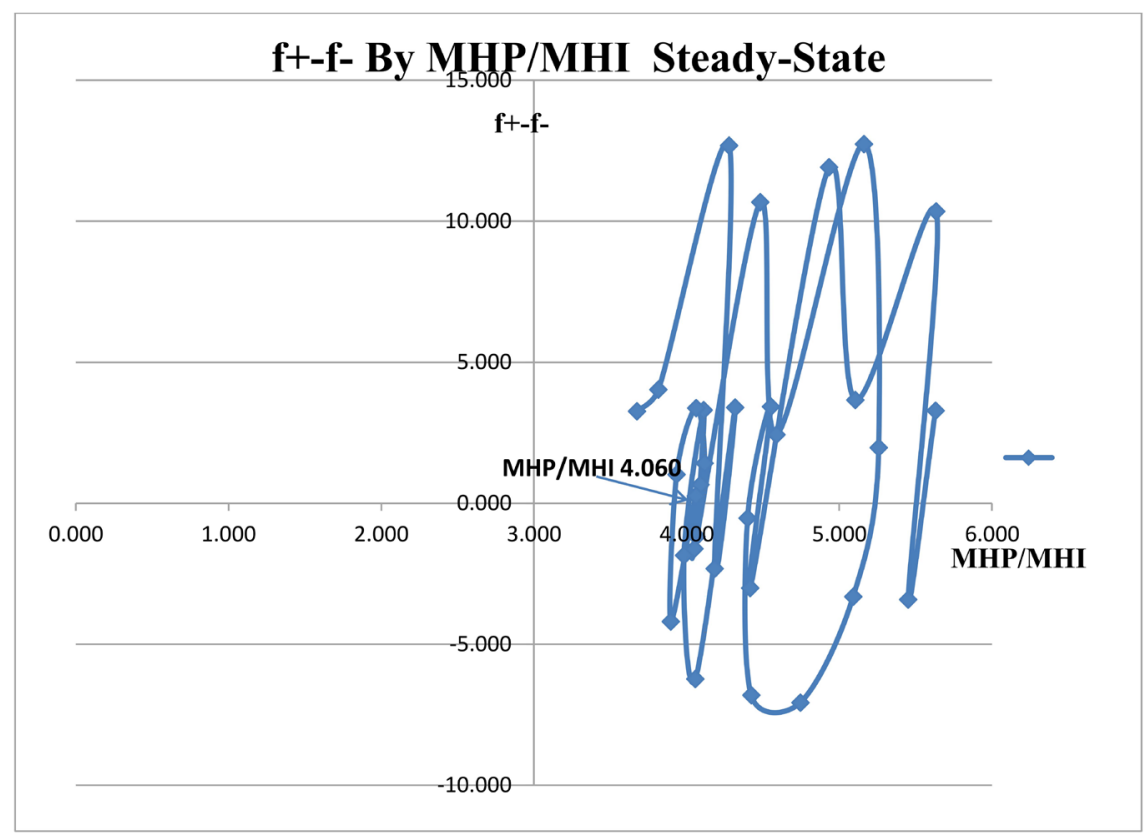

Figure 9. Differences in rates of change of median house prices and median household income. Source: Data items from Federal Reserve Bank of St. Louis, FRED database and author computation. 

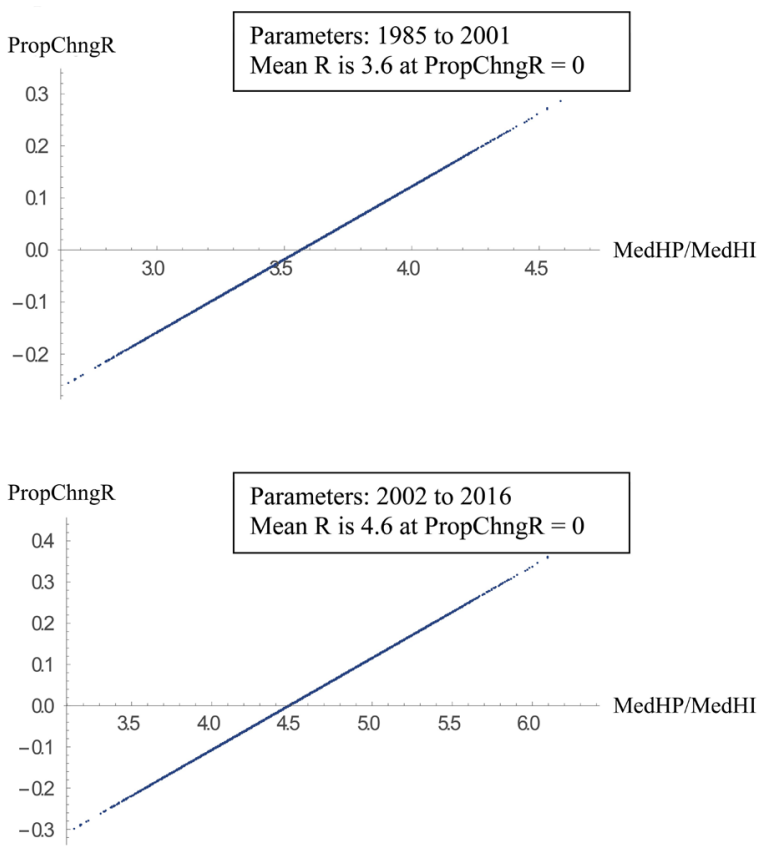

Figure 10. Simulations results for parameters between 1985 to 2001 and 2002 to 2016. Note: The simulated means are statistically significantly different at the 1 percent level $(t=2.1)$.

One implication of these results is that the U.S. housing market is in need of a house price correction and may be presently in a significant house price bubble that is unrelated to the foundations of the demand for housing. Thus the housing market has been pushed far from equilibrium with the natural adjustment forces being unable to work to restore a stable equilibrium. As in the housing price crash after mid-2006, house prices may have to fall considerably to restore a stable equilibrium. Without a significant and sustainable growth in median household income near 5+ percent, housing prices may face another collapse. And, if monetary policy does not begin an immediate adjustment to normalization of interest rates and the Fed reduce its holdings of GSE MBS and debt and Treasury debt, the bubble may get worse and likely burst in a destabilizing way as in 2006 exacerbating a shock to expectations. ${ }^{4}$

${ }^{4}$ In an article in 2008, David Stockman [18], a former Director of Management and Budget in the Reagan Administration, referred to the notion of "fast money." By "fast money", Stockman is referring to professional investors like hedge funds and private equity firms. To his point, global investment firm Blackstone ( $\underline{\mathrm{BX}}$ ) has spent more than $\$ 2.5$ billion on 16,000 homes to manage as rentals, according to Bloomberg. It's now the country's largest investor in single-family homes to manage as rentals, with properties in nine markets. And Blackstone is joined by others like Colony Capital LLC and Two Harbors Investment Corp. $(\underline{\mathrm{SBY}})$ in trying to turn this market into a new institutional asset class, Bloomberg reports.

"As soon as the Fed has to normalize interest rates, housing prices will stop appreciating and they'll probably head down," he explains. "The fast money will sell as quickly as they can and the bubble will pop almost as rapidly as it's appeared. I don't know how many times we're going to do this, and the only people who benefit are the top one percent-the hedge funds, the LBO funds, the fast money people who come in for a trade, make a quick buck, and move along to the next bubble."

Blog: Economics of Contempt

Post: The Unofficial List of Pundits/Experts Who Were Wrong on the Housing Bubble Link: http://economicsofcontempt.blogspot.com/2008/07/official-list-of-punditsexperts-who.html 


\section{Conclusions}

Approaches to assessing house price stability, or better yet, instability of house price fluctuations and booms and busts, have concentrated on analyzing variations in median house prices and house price indices such as S\&P-Case-Shiller or CoreLogic time series. This approach has not yielded much in the way of analytical results or in identifying equilibrium house price changes. It has been thought during the house price boom of 2003-2006 that 10 percent or greater annual increases in median house prices was to be expected indefinitely and that these represented sustainable equilibrium house price appreciation. Today, in June 2017, this notion is being reconsidered and revised to something much less than 10 percent annual appreciation, usually around 5 percent at most.

The approach taken in this study is to recognize that households choose housing based on a number of factors, but like other durable consumer goods, household income, expected long run household income, mortgage rates and life-cycle stage, are the primary determinants of the choice of how much households are willing to spend on housing. The conclusions of this approach are: 1) in equilibrium median house prices should appreciate at approximately the same rated as median household median incomes; 2) movements far away from the equilibrium value of median house price-median income ratio are not sustainable and are unstable. If housing policies, supported by monetary policy, had been more closely aligned to increase employment and ultimately household incomes, house prices would have followed demand as it picked up after the house price collapsed as households became more willing to maintain housing goals; 3 ) as a corollary to 2), house prices will have a stable appreciation rate as long as the median house price-median household income ratio stays within the range of 3.6 to 4.2 times; if the ratio falls outside these boundaries, house prices will rise or fall precipitously, accelerating the farther the ratio gets from equilibrium; and, 4) the ratio of median house prices to median household income follows what is referred in the field of the dynamics of chemical reactions as a "catalytic loop". This means that the changes in the ratio feedback on the ratio and so change it. These catalytic loops become more evident as the ratio moves near equilibrium. This feedback is perhaps the most apparent cause of the instability in house prices as the ratio becomes farther from equilibrium. In brief, there is a weakening in the forces that are present as the ratio moves farther from equilibrium to bring it back without major changes, usually collapse of house prices (the bubble bursts). The same can be said as the ratio moves to excessively smaller values so that prices decline precipitously. These conclusions are also supported by the decoupling of median house price changes from median household income changes.

A housing policy prescription follows from the analysis presented here. The Fed policy adopted during the Great Recession to lower interest rates to near zero and to provide funds for the housing market by the Fed purchases of trillions of dollars of residential mortgage-backed securities via its QEs in order to 
restore house prices to their former peak levels was and is a misguided policy. The policy assumes that the ratio of median house prices to median household income of $5+$ times at the peak of the house price boom is a stable steady-state equilibrium-clearly it was not and is not currently at a ratio of 5.63. Trying to achieve house prices consistent with the peak and a ratio that is unstable has cost taxpayers several trillion dollars of misplaced resources without any benefits of income and employment growth.

From the analysis and results presented here, I conclude that, as of the beginning of June 2016, the evidence is overwhelming that housing price appreciation is in a bubble that will likely lead to significant declines in house price appreciation if not in house prices. An important policy recommendation to mitigate the severity of these declines is for the Fed and monetary policy to begin to normalize interest rates by curtailing the reinvestment and purchases of agency mortgage backed securities and Treasury securities immediately, thus raising rates and absorbing the excess funds from the financial markets now going into residential real estate.

The policy prescription: abandon the current expansionary policy of reinvesting maturing Treasury Securities, GSE MBS and debt, and allow interest rates to set their own level consistent with a growing economy, not a stagnant economy.

\section{Acknowledgements}

I would like to thank participants at sessions where drafts of this paper have been presented for their helpful comments. I would like to extend a special thank you to Dr. Anthony Sanders, Distinguished Professor of Finance, School of Business, George Mason University for his suggestion to more extensively model stochastic properties of median house prices and median household income and to Dr. Gary Fissel of the Division of Insurance and Research, FDIC, Washington, D.C.

\section{Conflicts of Interest}

The author declares no conflicts of interest regarding the publication of this paper.

\section{References}

[1] Board of Governors of the Federal Reserve System (2020) Flow of Funds Accounts, Table B101, Various Years.

[2] National Association of Realtors (2019) Median Sales Price of Existing Homes. https://www.nar.realtor

[3] U.S. Census Bureau, May 26, 2016.

[4] Bertus, M., Hollans, H. and Swidler, S. (2008) Hedging House Price Risk with CME Futures Contracts: The Case of Las Vegas Residential Real Estate. The Journal of Real Estate Finance and Economics, 37, 265-279. https://doi.org/10.1007/s11146-008-9129-Z

[5] Englund, P., Hwang, M. and Quigley, J.M. (2002) Hedging Housing Risk. The 
Journal of Real Estate Finance and Economics, 24, 167-200. https://doi.org/10.1023/A:1013942607458

[6] Fan, G.-Z., Pu, M. and Ong, S. (2012) Optimal Portfolio Choices, House Risk Hedging and the Pricing of Forward House Transactions. The Journal of Real Estate Finance and Economics, 45, 3-29. https://doi.org/10.1007/s11146-011-9323-2

[7] Lee, C., Stevenson, S. and Lee, M.-L. (2014) Futures Trading, Spot Price Volatility and Market Efficiency: Evidence from European Real Estate Securities Futures. The Journal of Real Estate Finance and Economics, 48, 299-322. https://doi.org/10.1007/s11146-012-9399-3

[8] Shiller, R. (1990) Speculative Prices and Popular Models. Journal of Economic Perspective, 4, 55-65. https://doi.org/10.1257/jep.4.2.55

[9] Voicu, C. and Seiler, M.J. (2013) Deriving Optimal Portfolios for Hedging Housing Risk. The Journal of Real Estate Finance and Economics, 46, 379-396. https://doi.org/10.1007/s11146-011-9328-x

[10] Wong, S., Yiu, C., Tse, M. and Chau, K. (2006) Do the Forward Sales of Real Estate Stabilize Spot Prices? The Journal of Real Estate Finance and Economics, 32, 289-304. https://doi.org/10.1007/s11146-006-6803-x

[11] Wong, S., Chau, K. and Yiu, C. (2007) Volatility Transmission in the Real Estate Spot and Forward Markets. The Journal of Real Estate Finance and Economics, 35, 281-293. https://doi.org/10.1007/s11146-007-9037-7

[12] Abreu, D. and Brunnermeier, M. (2003) Bubbles and Crashes. Econometrica, 71, 173-204. https://doi.org/10.1111/1468-0262.00393

[13] Flood, R. and Hodrick, R. (1990) On Testing for Speculative Bubbles. Journal of Economic Perspectives, 4, 85-101. https://doi.org/10.1257/jep.4.2.85

[14] Stiglitz, J. (1990) Symposium on Bubbles. Journal of Economic Perspectives, 4, 13-18. https://doi.org/10.1257/jep.4.2.13

[15] Evans, G. (1991) Pitfalls in Testing for Explosive Bubbles in Asset Prices. American Economic Review, 4, 922-930.

[16] Prigogine, I. and Stengers, I. (1984) Order out of Chaos, Man's New Dialogue with Nature. Bantam Books, New York.

[17] Sugihara, G., May, R., Ye, H., Hsieh, C., Deyle, E., Fogarty, M. and Munch, S. (2012) Detecting Causality in Complex Ecosystems. Science, 338, 496-500. https://doi.org/10.1126/science.1227079

[18] Stockman, D. (2008) Economics of Contempt: The Unofficial List of Pundits/Experts Who Were Wrong on the Housing Bubble. http://economicsofcontempt.blogspot.com/2008/07/official-list-of-punditsexpertswho.html 